\section{BSDHT}
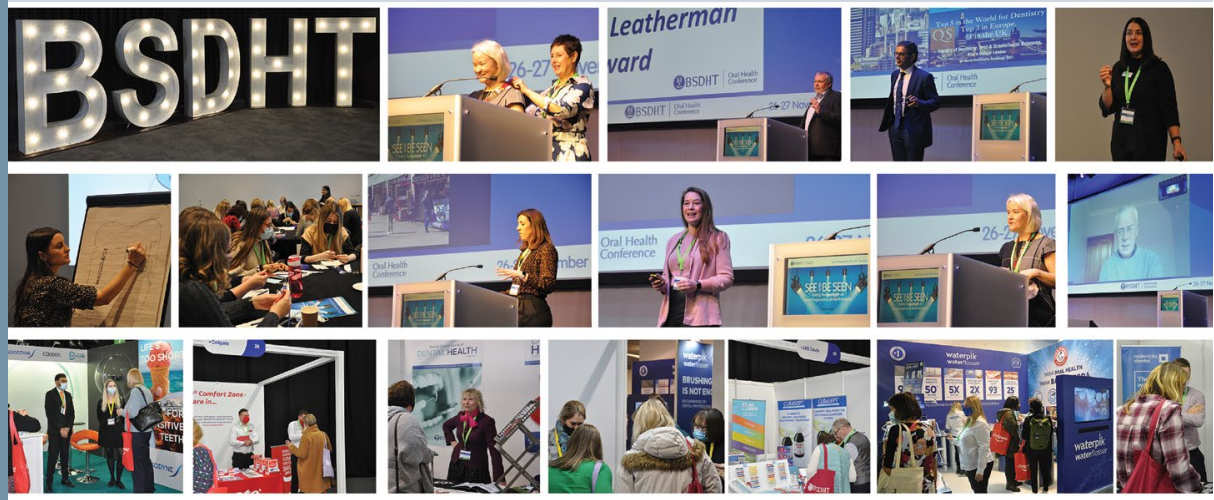

\section{ORAL HEALTH CONFERENCE A BIG SUCCESS}

The British Society of Dental Hygiene and Therapy (BSDHT) were delighted to announce that 2021's Oral Health Conference (OHC) was everything they had hoped for and more!

Held at the SEC Glasgow from 26-27 November 2021, the OHC was filled with learning, laughter and lots of chances for delegates to acquire new skills. Plus, the show gave everyone a much-needed chance to reconnect with colleagues, make new friends and, most importantly, see once again why the profession is such an exciting and important part of modern dentistry.

If you would like to find out more about the sessions you didn't attend or if you simply want to recap some of the best moments from the weekend, BSDHT may be contacted for further information.

Visit www.bsdht.org.uk, call 01788 575050 or email enquiries@bsdht.org.uk.

\title{
Julie Deverick passes the presidential toreh
}

One of the highlights of 2021's Oral Health Conference (OHC) hosted by the British Society of Dental Hygiene and Therapy (BSDHT) was that Julie Deverick, Immediate Past President, could finally officially hand the torch over to current President Diane Rochford.

Though Diane has been in this role for a year now, this was a touching moment for everyone at the conference, especially as Diane and Julie were thrilled to be able to take this all-important ceremonial step in person.

Julie's contributions to the Society have ensured an excellent legacy, while Diane's forward-thinking attitude means that during her next year of presidency, there are sure to be many more fantastic steps forward.

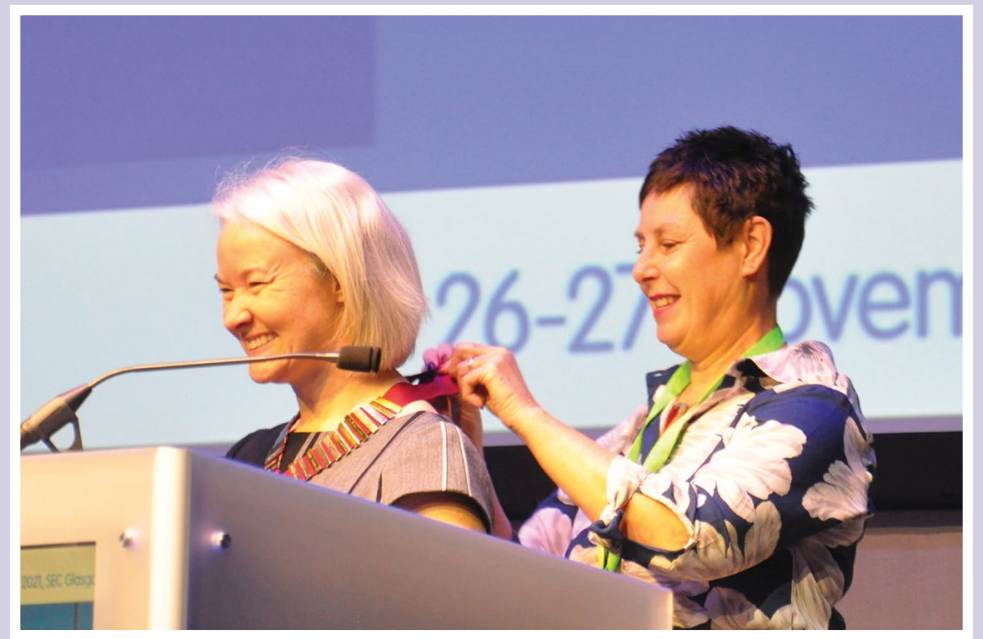

BADN HOLDS AGM AND ANNIVERSARY DRINKS RECEPTION

The British Association of Dental Nurses (BADN) was delighted to be able to hold both its 2021 Annual General Meeting and its delayed 80th Anniversary Drinks Reception on 23 November 2021 at the Naval and Military Club, London.

The $80+1$ Anniversary Drinks Reception which followed the AGM was attended by BADN members and guests from the BDA, GDC, CGDent, HEE, OHF, ONG, OTA, BADT, NEBDN, DTA, Simplyhealth, \{my\}dentist, BUPA, the dental press, dental trade companies, Parliament Hill (providers of the BADN Rewards Scheme) and CFC (underwriters of the BADN indemnity scheme).

Former BADN Chairman Dr Debbie Reed who during 2020 had been awarded a Doctorate in Education, the BADN Outstanding Contribution award and the FGDP(UK) Janet Goodwin DCP Award, received the awards from BADN President Jacqui Elsden and the President of the new College of General Dentistry, Dr Abhi Pal.

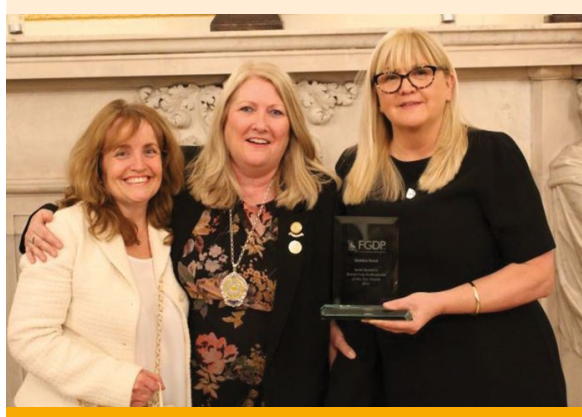

Retiring BADN Chairman Jane Dalgarno (left), President Jacqui Elsden (centre) and former Chairman Dr Debbie Reed

\section{CALLING KEEN WRITERS}

Would you like to write for BDJ Team? The Editor, Kate Quinlan, is currently looking for new reader panellists and contributors. Perhaps you could review a dental event or course; you may wish to be interviewed about your career history in dentistry; or you may like to share the results of an audit or research. Please email k.quinlan@nature.com. 